Disponível em:

http://editora.unoesc.edu.br/index.php/race

Race, Joaçaba, v. 15, n. 3, p. 945-968, set./dez. 2016

\title{
DETERMINANTES DO NÍVEL DE DISCLOSURE DAS COMBINAÇÕES DE NEGÓCIOS REALIZADAS PELAS EMPRESAS BRASILEIRAS DE CAPITAL ABERTO
}

Disclosure Level Determinants of Business Combinations Performed by Brazilian Public Companies

Maíra Melo de Souza

E-mail: mairameloufsc@gmail.com Doutora em Administração e Mestre em Contabilidade pela Universidade Federal de Santa Catarina; Professora do Departamento de Ciências Contábeis da Universidade

Federal de Santa Catarina.

Suliani Rover

E-mail: sulianirover@gmail.com

Doutora em Controladoria e Contabilidade pela Universidade de São Paulo e Mestre em Contabilidade pela Universidade Federal de Santa Catarina; Professora do Departamento de Ciências Contábeis da Universidade Federal de Santa Catarina.

José Alonso Borba

E-mail: jalonso@cse.ufsc.br

Doutor em Controladoria e Contabilidade pela Universidade de São Paulo; Professor do Departamento de Ciências Contábeis da Universidade Federal de Santa Catarina. Endereço para contato: Campus Reitor João David Ferreira Lima, s/n, 88040-900, Trindade, Florianópolis, Santa Catarina, Brasil.

Recebido em 06 de maio de 2015. Aceito em 04 de julho de 2016. 


\section{Resumo}

O objetivo nesta pesquisa foi identificar fatores determinantes para explicar o nível de disclosure das combinações de negócios realizadas pelas empresas brasileiras de capital aberto no período entre 2010 e 2013. Foram analisadas 202 combinações de negócios. Por meio de um modelo de regressão linear múltipla foram testadas as variáveis: price to book, tamanho, rentabilidade, endividamento, goodwill relativo, porte relativo, ano em que ocorreram as combinações de negócios, setor de atuação da empresa adquirente e quantidade de combinações realizadas por empresa. Os resultados demonstraram que o nível de evidenciação das combinações de negócios, na amostra pesquisada, é influenciado negativamente pelo valor do goodwill reconhecido na transação (goodwill relativo) e positivamente pela proporção da contraprestação em relação ao valor do ativo total (porte relativo).

Palavras-chave: Combinação de negócios. Disclosure. Goodwill.

\section{Abstract}

The objective with this research was to identify determining factors to explain the level of disclosure of business combinations carried out by the Brazilian public companies in the period between 2010 and 2013. Two hundred two business combinations were analyzed. Through a multiple linear regression model variables were tested: price to book, size, profitability, debt, relative goodwill, relative size, when the business combinations ioccurred, operating segment of the acquiring company and the amount of combinations per company. The results showed that the level of disclosure of business combinations, in the surveyed sample, is negatively influenced by the amount of goodwill recognized on the transaction (goodwill relative) and positively by the proportion of the consideration in relation to the value of total assets (relative size).

Keywords: Business combinations. Disclosure. Goodwill.

\section{INTRODUÇÃO}

Com o desenvolvimento global, normalmente as empresas buscam maneiras de obter vantagens competitivas, estas que podem assumir a forma de aumento da sinergia por meio da combinação de duas ou mais empresas (MORTENSEN, 1994). Essas operações são conhecidas como combinações de negócios ou reorganizações societárias; como exemplos pode-se citar as incorporações, as fusões e as aquisições.

Considerando a importância das combinações de negócios no contexto empresarial, os órgãos normalizadores se empenham no desenvolvimento de normas de contabilidade que possam refletir a realidade econômica dessas transações. 
No Brasil, o Comitê de Pronunciamentos Contábeis (CPC), órgão engajado em promover a convergência das normas brasileiras com as normas internacionais do International Accounting Standards Boards (IASB), emitiu em 2009 a primeira versão do pronunciamento contábil CPC-15, correlacionado à norma internacional IFRS 3 do IASB; atualmente a versão é o CPC-15 R1.

Nesse contexto, um dos objetivos do pronunciamento contábil CPC-15 R1/2011 é determinar quais informações precisam ser divulgadas para possibilitar aos usuários das demonstrações contábeis uma avaliação da natureza e dos efeitos financeiros decorrentes das combinações de negócios (COMITÊ DE PRONUNCIAMENTOS CONTÁBEIS, 2011).

A referida norma de contabilidade teve sua primeira versão emitida pelo Comitê de Pronunciamentos Contábeis (CPC) em 2009 para vigência a partir dos exercícios sociais encerrados em 2010. Essa norma, assim como as demais emitidas pelo CPC, faz parte do processo de convergência do Brasil aos padrões internacionais do IASB.

O conceito formal do pronunciamento contábil CPC-15 R1/2011 explana que “[...] uma combinação de negócios é uma operação por meio do qual um adquirente obtém o controle de um ou mais negócios, independentemente da forma jurídica da operação.”

Nesse contexto, o disclosure das informações sobre as combinações de negócios exerce um papel importante no sentido de fornecer aos usuários os detalhes pertinentes às políticas contábeis adotadas e aos valores atinentes às transações realizadas (SHALEV, 2009).

Neste trabalho adota-se a perspectiva de que as necessidades de informação acerca das combinações vão além das exigências estabelecidas pelo CPC-15 R1 (COMITÊ DE PRONUNCIAMENTOS CONTÁBEIS, 2011). A ideia subjacente é que se as empresas estiverem interessadas em passar informações completas (um dos atributos da informação contábil conforme a estrutura conceitual do CPC), elas divulgarão todas as informações necessárias para compreender a transação realizada pela empresa.

Para Schipper (2007), possivelmente pela razão de não existir uma vasta teoria tratando do disclosure obrigatório, várias questões ainda necessitam ser pesquisadas no que compete a como evidenciar as informações obrigatórias.

Grande parte dos trabalhos a respeito de disclosure foi realizada em países com modelo contábil anglo-saxão e são pertinentes ao disclosure voluntário. Ainda existem poucos estudos tratando do disclosure obrigatório em países emergentes, nos quais o mercado de capitais é menos desenvolvido (SCHIPPER, 2007; HASSAN et al., 2009; BABOUKARDOS; RIMMEL, 2014). 
No Brasil, diante do desafio que a norma que trata de combinações de negócios apresenta no contexto de convergência aos padrões do IASB, estudos tratando do disclosure obrigatório pertinente ao CPC-15 R1 (COMITÊ DE PRONUNCIAMENTOS CONTÁBEIS, 2011) ganham relevância.

Diante do tema exposto, elaborou-se o seguinte problema de pesquisa: quais fatores são determinantes para explicar o nível de disclosure das combinações de negócios realizadas pelas empresas brasileiras de capital aberto?

O objetivo neste estudo foi identificar fatores determinantes para explicar o nível de disclosure das combinações de negócios realizadas pelas empresas brasileiras de capital aberto.

A divulgação contábil desempenha um papel essencial na redução da assimetria informacional no contexto da teoria da agência (KLANN; BEUREN; HEIN, 2015). A ideia subjacente é que as empresas que realizam melhores níveis de disclosure estão contribuindo para a transparência da sua situação econômica e financeira, reduzindo a assimetria de informação entre aqueles que tomam as decisões e aqueles que podem ser afetados por tais decisões.

Nakayama e Salotti (2014) verificaram um baixo nível de disclosure realizado por empresas brasileiras, analisando combinações de negócios realizadas no ano 2010. O presente estudo abrange as combinações de negócios ocorridas no período entre 2010 e 2013, expandindo, assim, o número de observações.

O restante do trabalho está organizado da seguinte maneira: na seção 2 apresenta-se o referencial teórico, no qual se abordam os temas conflitos de interesses e evidenciação das combinações de negócios. A seção 3 contempla a metodologia utilizada na pesquisa, na seção 4 estão apresentados os resultados do estudo, e na seção 5 estão contempladas as conclusões da pesquisa.

\section{REFERENCIAL TEÓRICO}

\subsection{CONFLITOS DE INTERESSES}

Shleifer e Vishny (1997) explicam que os conflitos de agência ocorrem em virtude da separação entre propriedade e controle, em que o agente que pratica as ações na empresa pode ter interesses alheios àqueles dos acionistas que não estão à frente das decisões.

Em relação à estrutura de controle, existem países em que a maioria das empresas possui o controle concentrado, ou seja, a maior parcela das ações com direito a 
voto (ordinárias) está concentrada nas mãos de um único acionista. E existem países com característica de dispersão acionária; nesse caso, a maioria das ações com direito a voto encontra-se diluída no mercado acionário. Nos dois tipos de estrutura de controle pode ocorrer o conflito de interesses. Nas empresas em que o controle é concentrado o conflito pode ocorrer entre os acionistas controladores e não controladores. Já em empresas em que o controle é disperso, o conflito pode acontecer entre os gestores e os acionistas (LA PORTA et al., 2000).

Nesse ambiente, em acordo com a teoria da agência explanada por Jensen e Meckling (1976), o gerenciamento de resultados pode ser utilizado em decorrência desses conflitos de interesses. Em outras palavras, aquele que detém o controle das decisões na empresa pode gerenciar suas escolhas no que se refere aos registros contábeis de forma a demonstrar um resultado condizente com seus propósitos e ambições.

Martinez (2001) ressalta que é necessário ter em mente que existe diferença entre o gerenciamento que se constitui uma prática fraudulenta e aquele que envolve julgamentos e estimativas viesadas, pois nesse último as normas contábeis facultam ao gestor a possibilidade de realização de julgamentos, a exemplo pode-se citar a estimativa da vida útil esperada em ativos de longa duração. Já nos casos de fraude o agente comete um ato que transgride leis, normas e princípios de contabilidade, portanto, um crime.

Percebe-se que é suscetível a ocorrência de fraudes quando existe a faculdade de julgamento por parte de gestores ou controladores, contudo os atos fraudulentos não se restringem apenas a esse cenário.

A esse respeito, Healy e Wahlen (1999) expõem que existem muitas maneiras de o agente exercer julgamento nas demonstrações contábeis. Por exemplo, o julgamento é necessário para estimar inúmeros eventos econômicos futuros esperados, como a vida e os valores de resgate de ativos de longo prazo, as obrigações relacionadas aos fundos de pensão, os impostos diferidos, as perdas estimadas provenientes de créditos de liquidação duvidosa e o impairment de ativos. Os autores ressaltam que há várias outras escolhas decorrentes de possibilidades das normas de contabilidade que podem ser decididas mediante julgamento por parte dos gestores.

No que compete às escolhas contábeis, Watts (1992) explica que de acordo com a situação atual da empresa e os incentivos dos gestores no julgamento de determinadas normas, podem prevalecer as escolhas que venham ao encontro de seus objetivos e ambições.

A ideia subjacente é que, apesar de nem todas as escolhas contábeis envolverem gerenciamento de resultados e da extensão do gerenciamento de resultados 
poder se estender além das escolhas provenientes das normas de contabilidade, as implicações das escolhas contábeis para atingir um objetivo são consistentes com a ideia de gestão de lucro (FIELDS; LYS; VINCENT 2001). Em outras palavras, nos casos em que as normas contábeis facultam poder de julgamento por parte dos agentes, conforme mencionado por Martinez (2001), existe espaço para o gerenciamento de resultados.

Nesse contexto, Bushman et al. (2000) entendem a divulgação de informações ao mercado como um meio de reduzir a assimetria informacional, associando a divulgação com mecanismos de governança corporativa.

Governança corporativa constitui um conjunto de mecanismos que visam assegurar que os fornecedores de recursos receberão novamente o retorno do seu investimento. Os riscos de os recursos não serem bem empregados decorrem da separação entre propriedade e controle; essa concepção possui respaldo na teoria da agência (SILVEIRA, 2004).

É possível depreender que a transparência das informações, por meio de melhores níveis de disclosure, contribui à redução da assimetria informacional, mitigando os problemas de agência e contribuindo para a boa governança corporativa (PATEL; BALIC; BWAKIRA, 2002).

Em países desenvolvidos os governos investem uma grande quantidade de recursos visando promover maior transparência e garantir que os acionistas não controladores recebam informações confiáveis sobre o valor das empresas e motivar os gestores a maximizar o valor da empresa em vez de perseguir seus objetivos pessoais (BUSHMAN; SMITH, 2003).

O Brasil possui a característica de controle acionário concentrado, dessa maneira, normalmente, existe um acionista detentor da maioria das ações, ou um bloco de acionistas que exerce o controle da empresa (SILVEIRA et al., 2004).

Em países em que o nível de disclosure é baixo, a concentração de propriedade é prejudicial aos acionistas não controladores, uma vez que reduz a transparência (PATEL; BALIC; BWAKIRA, 2002).

A importância do adequado disclosure das informações de caráter obrigatório nas notas explicativas que acompanham as demonstrações contábeis é crucial, considerando-se que os usuários externos precisam dessas informações para analisar a situação da empresa.

Em se tratando de combinações de negócios, a transparência das informações também é importante, considerando-se que, normalmente, referem-se a transa- 
ções envolvendo valores elevados e com grande impacto na economia de um país (SHALEV, 2009).

Nessa perspectiva, o disclosure das informações pertinentes às combinações de negócios contribui para a redução da assimetria informacional no mercado, colaborando para as boas práticas de governança corporativa.

\subsection{EVIDENCIAÇÃO DAS COMBINAÇÕES DE NEGÓCIOS}

Combinação de negócios é uma operação na qual um adquirente obtém o controle de um ou mais negócios independente da existência de contraprestação. Nos casos em que há uma contraprestação em troca do controle, ela pode ser feita por meio de pagamento ou promessa de pagamento em dinheiro ou ações. Por outro lado, nas situações em que não existe contraprestação a cumprir por parte do adquirente, a transação é realizada por meio unicamente contratual (BABOUKARDOS; RIMMEL, 2014). São exemplos de combinações de negócios: fusões, incorporações e aquisições realizadas entre empresas.

O constante surgimento de novos mercados externos e a rapidez com que eles sofrem mutações tornam as fusões e aquisições de empresas, muitas vezes, o meio mais rápido e eficiente para se chegar a mercados mais desenvolvidos (GODOY; SANTOS, 2006). Isso pode ter relação com o fato de que adquirir uma empresa em andamento permite entrar em um mercado com uma linha já desenvolvida, sendo esta uma estratégia de crescimento da adquirente (FOGG, 1976).

Em sua pesquisa, Healy, Palepu e Ruback (1992) analisaram o desempenho pós-combinação das 50 maiores fusões e incorporações ocorridas nos Estados Unidos no período de 1979-1984 e demonstraram melhorias no desempenho das empresas. Os autores relataram maiores índices de produtividade e aumentos nos retornos de fluxo de caixa operacional no período após a respectiva combinação de negócios.

Considerando a importância que as combinações de negócios representam para o meio econômico e social, os órgãos normatizadores se empenham no desenvolvimento de normas de contabilidade que possam refletir a realidade econômica dessas transações. Nesse intento, o IASB possui a norma IFRS 3 tratando dessas transações. O Brasil também adota essa norma por meio do CPC-15 R1 (correlacionada à norma do IASB IFRS 3).

Contudo, a norma IFRS 3 é considerada uma das mais complexas do IASB (BABOUKARDOS; RIMMEL, 2014). A complexidade começa pelo método de aquisição que exige a utilização do valor justo (fair value) na mensuração dos ativos e 
passivos da adquirida (DORATA; ZALDIVAR, 2010; MARIO et al., 2011; BABOUKARDOS; RIMMEL, 2014), determinando, também, que os intangíveis identificáveis, passivos adquiridos, goodwill ou ganho por compra vantajosa sejam reconhecidos na data de aquisição.

Em todos os casos de combinações de negócios é necessário identificar a figura do controlador, ou seja, uma das partes envolvidas na operação deverá ser identificada como o adquirente (aquele que adquiriu o controle na combinação de negócios realizada). A referida norma do IASB (no Brasil CPC-15 R1) determina que o adquirente utilize o método de aquisição para contabilizar os fatos relativos à combinação de negócios realizada.

Pelo método de aquisição, o adquirente deverá realizar a avaliação do valor justo dos ativos e passivos da empresa adquirida na data de aquisição (data em que o controle da adquirida foi transferido para a adquirente). Essa análise possibilitará ao adquirente apurar a diferença entre o valor justo e o valor contábil dos ativos e passivos adquiridos.

Nesse contexto, uma das preocupações a respeito da utilização do método de aquisição nas combinações de negócios é a subjetividade inerente à avaliação do valor justo (fair value) dos ativos e passivos assumidos na data de fechamento do negócio (DORATA; ZALDIVAR, 2010; MARIO et al., 2011; BABOUKARDOS; RIMMEL, 2014).

Considerando a subjetividade da avaliação do valor justo, a evidenciação das informações relativas às combinações de negócios é crucial para os usuários externos (SHALEV, 2009; MARIO et al., 2011; BABOUKARDOS; RIMMEL, 2014). De acordo com o CPC-15 R1 (COMITÊ DE PRONUNCIAMENTOS CONTÁBEIS, 2011), o adquirente deve divulgar informações que permitam aos usuários das demonstrações contábeis avaliarem a natureza e os efeitos financeiros das combinações de negócios.

O referido pronunciamento contábil do CPC ainda complementa com a seguinte orientação: se as divulgações exigidas por este e outros pronunciamentos, interpretações e orientações do CPC não forem suficientes para cumprir os objetivos estabelecidos nos itens 59 e 61, o adquirente deve divulgar toda e qualquer informação adicional necessária para que esses objetivos sejam cumpridos.

Dessa maneira, a preocupação com a informação completa está explícita na estrutura conceitual adotada pelo CPC. Considerando o contexto de um mercado de capitais emergente como o Brasil e os impactos que as combinações de negócios podem gerar no País, entendem-se como relevantes os estudos que visam identificar fatores que podem influenciar em maior ou menor nível de divulgação o contexto brasileiro. 


\section{METODOLOGIA}

O estudo se enquadra em teórico-empírico e no que compete aos objetivos é exploratório e descritivo. A abordagem do problema é qualitativa e quantitativa, visto que foi necessária a análise qualitativa das notas explicativas, por meio da Análise de Conteúdo (BARDIN, 2004), para obtenção da variável dependente utilizada neste estudo (nível de disclosure das combinações de negócios), e, também, foram utilizadas ferramentas estatísticas, como a Regressão com Dados em Painel, para responder ao problema de pesquisa.

Nessa metodologia, na pesquisa utilizaram-se de procedimentos qualitativos e quantitativos no tratamento dos dados, visto que se realizou uma análise das informações divulgadas nas notas explicativas das companhias, com a finalidade de se mensurar o nível de evidenciação, e, posteriormente, utilizou-se a técnica estatística de regressão linear múltipla para se verificar se as variáveis testadas possuem influência sobre o nível de evidenciação das combinações de negócios. Essa abordagem de pesquisa é conhecida como estratégia de triangulação.

Conforme Azevedo et al. (2013), com base na triangulação pode-se combinar métodos e fontes de coleta de dados qualitativos e quantitativos e diferentes métodos de análise de dados, com o intuito de contribuir para a investigação sob diversas perspectivas e aprofundando a compreensão sobre o fenômeno estudado.

A obtenção dos dados foi realizada, predominantemente, por meio documental mediante notas explicativas publicadas na Bolsa de Valores Mercadorias e Futuros de São Paulo (BM\&FBOVESPA). O período analisado foi entre 2010 e 2013.

\subsection{SELEÇÃO DA AMOSTRA}

A informação relativa às empresas que realizaram combinações de negócios, no papel de adquirente, no período entre 2010 e 2013, foi obtida por meio dos fatos relevantes divulgados no endereço eletrônico da Comissão de Valores Mobiliários (CVM). Assim, foram verificados todos os fatos relevantes que anunciavam fusões, incorporações, aquisições e cisões e selecionados apenas os casos em que a combinação de negócios resultou em transferência de controle. Compuseram a amostra apenas as empresas que exerceram o papel de adquirente na combinação de negócios.

Com base no critério exposto, foram identificadas 202 combinações de negócios, que constituíram objeto de estudo na presente pesquisa. 


\subsection{OBTENÇÃO DO ÍNDICE DE DISCLOSURE DAS COMBINAÇÕES DE NEGÓCIOS}

Para obter o índice de disclosure de cada observação componente da amostra, primeiramente foi necessário elaborar uma métrica abrangendo as informações que precisam ser divulgadas pelas empresas referentes às combinações de negócios realizadas.

De acordo com o CPC-15 R1 (COMITÊ DE PRONUNCIAMENTOS CONTÁBEIS, 2011), o adquirente deve divulgar informações que permitam aos usuários das demonstrações contábeis avaliarem a natureza e os efeitos financeiros de combinação de negócios que ocorra: durante o período de reporte corrente ou após o final do período de reporte, mas antes de autorizada a emissão das demonstrações contábeis.

Nakayama (2012) utilizou uma métrica com base nas determinações do CPC15 (COMITÊ DE PRONUNCIAMENTOS CONTÁBEIS, 2009). A base para a métrica do referido autor foi a primeira versão do pronunciamento contábil relativo a combinações de negócios. Seu trabalho objetivou medir o nível de evidenciação das combinações de negócios no ano 2010 e identificar fatores determinantes do nível de evidenciação realizado pelas empresas brasileiras.

Souza (2015) realizou uma abertura das exigências contidas no CPC-15 R1 (COMITÊ DE PRONUNCIAMENTOS CONTÁBEIS, 2011), visando a um detalhamento de informações sobre as combinações de negócios, e elaborou uma métrica de pesquisa para verificar o nível de disclosure das combinações de negócios.

De acordo com Souza (2015), a intenção foi contribuir para o atendimento do atributo de completeza preconizado pela Estrutura Conceitual para Elaboração e Divulgação de Relatório Contábil Financeiro do CPC (COMITÊ DE PRONUNCIAMENTOS CONTÁBEIS, 2011). Neste trabalho utilizou-se a métrica elaborada por Souza (2015).

Para obtenção do índice de evidenciação, adotou-se a metodologia utilizada nas pesquisas sobre combinações de negócios realizadas por Shalev (2009), Nakayama (2012) e Nakayama e Salotti (2014), atribuindo 1 para Evidenciação do Item, 0 para Não Evidenciação do Item e NA (Não se Aplica) para os casos em que determinado(s) item(s) da métrica não se aplica(m) ao respectivo(s) caso(s).

A partir da Análise de Conteúdo foi possível codificar as informações divulgadas nas notas explicativas das empresas e classificá-las de acordo com as categorias da métrica utilizada no estudo, auxiliando o processo de inferência sobre os conhecimentos relativos à variável analisada (BARDIN, 2004). 
Cada índice de disclosure foi obtido dividindo-se a quantidade evidenciada em notas explicativas pela quantidade total de itens da métrica aplicáveis de evidenciação. A fórmula (Equação 1) a seguir apresenta o procedimento utilizado no cálculo do índice relativo a cada combinação de negócio componente da amostra analisada nesta pesquisa.

Índice de Disclosure $=\underline{\text { Quantidade de itens evidenciados nas Notas Explicativas }}$

(Quantidade de itens da Métrica - Itens que Não se Aplicam)

Ressalta-se que cada combinação de negócios, componente da amostra, foi analisada individualmente. Dessa maneira, cada índice foi calculado de maneira individual, respeitando o respectivo ano em que ocorreu a transação.

\subsection{HIPÓTESES DE PESQUISA}

Visando responder ao problema formulado nesta pesquisa, foram testadas nove variáveis explicativas, sendo três variáveis de controle. As variáveis testadas foram: price to book, tamanho, rentabilidade, endividamento, goodwill, porte relativo, quantidade de combinações, setor e ano (essas três últimas são variáveis de controle).

\subsubsection{Price to Book}

H1: Empresas com maior índice price to book tendem a realizar um maior nível de disclosure das combinações de negócios.

Pae, Thornton e Welker (2005) acreditam que o nível do índice price to book é negativamente associado com os ganhos de conservadorismo contábil. Na concepção dos autores, as empresas tendem a divulgar más notícias de maneira mais oportuna quando esses índices são menores, pois os investidores tendem a confiar em maior conservadorismo nessas situações.

O índice price to book é medido pela razão entre o valor da ação e o valor patrimonial da empresa por ação; dessa maneira, ele representa quanto o mercado está valorizando a empresa em determinado momento.

Considerando que empresas com maiores índices price to book estariam recebendo maior valorização do mercado, espera-se que os gestores decidam por um maior nível de divulgação das suas combinações de negócios. 
Para operacionalizar a variável price to book, foi utilizado o respectivo índice referente ao final do período de reporte em que foi evidenciada a combinação de negócios. A fonte de dados foi por meio do ECONOMATICA®.

\subsubsection{Tamanho}

H2: Empresas maiores possuem um maior nível de disclosure das combinações de negócios do que empresas menores.

Palmer (2008), analisando 150 empresas australianas em seu estudo, mediu a qualidade do disclosure relativo à norma que trata do disclosure dos impactos da adoção inicial das normas contábeis australianas convergidas ao padrão IFRS. O autor constatou que o tamanho da empresa é um fator significativo para explicar a qualidade da evidenciação realizada pelas empresas.

Para operacionalizar a variável tamanho, utilizou-se o logaritmo natural do ativo total. A fonte de dados foi por meio do ECONOMATICA®.

\subsubsection{Rentabilidade}

H3: Empresas que possuem um maior grau de rentabilidade tendem a realizar um maior disclosure das combinações de negócios.

Cooper e Kaplan (1988) apontam a rentabilidade como um dos sinais de sucesso ou deterioração dos negócios. Nesse sentido, espera-se que a rentabilidade seja relevante para explicar o nível de disclosure das combinações de negócios.

Para operacionalizar a variável rentabilidade, foi utilizado o índice de rentabilidade do ativo (ROA) do respectivo período em que foi evidenciada a combinação de negócios. A fonte de dados foi por meio do ECONOMATICA ${ }_{\text {. }}$

\subsubsection{Endividamento}

H4: Empresas que possuem um maior grau de endividamento tendem a realizar um maior disclosure das combinações de negócios.

Holthausen e Leftwich (1983) verificaram em sua pesquisa uma associação entre as escolhas contábeis dos gestores e a alavancagem da empresa (utilização de 
capital de terceiros) no que se refere aos custos de contratação e monitoramento dos empréstimos obtidos. Nessa perspectiva, espera-se que o grau de endividamento seja relevante para explicar o nível de disclosure das combinações de negócios.

Para operacionalização da variável endividamento foi utilizado o índice de endividamento total calculado no respectivo período em que foi evidenciada a combinação de negócios. A fonte de dados foi por meio do ECONOMATICA®.

\subsubsection{Goodwill Relativo}

H5: Adquirentes que reconhecem maior proporção do goodwill em relação à contraprestação tendem a realizar um menor nível de disclosure das combinações de negócios.

A pesquisa de Shalev (2009) verificou que o nível de disclosure da combinação de negócios tende a diminuir quando o adquirente atribui altas quantias de goodwill em relação à contraprestação. O autor utilizou como proxy a proporção do goodwill em relação à contraprestação.

O estudo de Nakayama e Salotti (2014) também testou a variável proporção do goodwill em relação à contraprestação, no entanto ela não se mostrou significativa para explicar o nível de disclosure das combinações de negócios no ano 2010.

Considerando-se que neste trabalho se analisa uma amostra mais ampla de combinações de negócios, abrangendo o período entre 2010 e 2013, espera-se que a variável proporção do goodwill em relação à contraprestação se mostre significativa.

Para operacionalizar a variável Goodwill Relativo, utilizou-se a razão entre o valor do goodwill em relação ao valor da contraprestação acordada na combinação de negócios. Os dados foram obtidos nas notas explicativas das empresas da amostra.

\subsubsection{Porte Relativo}

H6: Adquirentes com maior proporção da contraprestação em relação ao total de seus ativos tendem a realizar um maior nível de disclosure das combinações de negócios.

Nakayama e Salotti (2014) utilizaram a variável Proporção da Contraprestação em Relação ao Ativo Total para representar a variável Porte Relativo da empresa no final do ano 2010. Essa variável se apresentou significativa no estudo realizado 
pelos referidos autores, que concluíram que as empresas parecem se preocupar em divulgar mais informações quanto maior significância representar o investimento em relação aos seus próprios ativos.

Para operacionalizar a variável Porte Relativo, utilizou-se a razão entre o valor da contraprestação e o valor do ativo total no final do respectivo período em que houve a evidenciação da combinação de negócios. Os dados relativos à contraprestação foram obtidos nas notas explicativas das empresas da amostra. Os dados pertinentes ao ativo total foram coletados no ECONOMATICA $®$.

\subsubsection{Variáveis de Controle}

As variáveis de controle possuem a função de controlar os efeitos de fatores que normalmente são relevantes na avaliação da variável dependente (BEHNAME; PAJOOHI; GHAHRAMANIZADY, 2012). Nessa concepção, foram utilizadas as seguintes variáveis de controle: ano em que ocorreram as combinações de negócios, setor de atuação da empresa adquirente e quantidade de combinações realizadas por empresa.

A variável Quantidade de combinações de negócios realizadas foi inserida em virtude de algumas empresas terem realizado várias combinações de negócios dentro do mesmo ano. Dessa maneira, optou-se por controlar essa situação inserindo-se a variável relativa à quantidade de combinações de negócios realizadas dentro de cada ano.

A variável dummy (setor de atuação) foi inserida baseando-se no estudo de Nakayama e Salotti (2014), visto que, em virtude de algumas empresas de capital aberto estarem propensas às normas de órgãos reguladores, como a Agência Nacional de Energia Elétrica (ANEEL) e o Banco Central do Brasil (BACEN), espera-se que empresas do setor financeiro e elétrico, reguladas, respectivamente, pelo Bacen e pela Aneel, apresentem maior nível de disclosure em relação às demais empresas.

A variável dummy relativa ao Ano em que ocorreram as combinações de negócios foi incluída considerando-se que os anos 2010 e 2011 podem ser entendidos como períodos em que as empresas brasileiras estavam se adaptando à norma CPC15, sendo sua adoção inicial. Já os anos 2012 e 2013 podem ser considerados períodos após a adoção inicial.

Ressalta-se que, apesar de na pesquisa ter-se analisado o período entre 2010 e 2013, não foi possível a realização de análise de dados em painel, considerando que os dados não permitem um acompanhamento da evidenciação das combinações de 
negócios por empresa ao longo do tempo, pois as empresas não realizam essas transações todos os anos.

\subsubsection{Modelo de Regressão}

A regressão linear múltipla diz respeito ao estabelecimento de duas ou mais variáveis explicativas (independentes), visando explicar determinado fenômeno representado por uma variável denominada dependente, também conhecida como prevista ou resposta (CUNHA; COELHO, 2009; FÁVERO et al., 2009).

Visando responder ao problema elaborado nesta pesquisa, foi utilizado um modelo de regressão linear múltipla, contendo como variável dependente o índice de disclosure das combinações de negócios, e como variáveis explicativas: price to book, tamanho, rentabilidade, endividamento, goodwill relativo, porte relativo, ano em que ocorreram as combinações de negócios, setor de atuação da empresa adquirente e quantidade de combinações realizadas por empresa. O software utilizado foi o Stata.

\section{RESULTADOS DA PESQUISA}

Na Tabela 1 apresentam-se os resultados relativos à quantidade de combinações de negócios realizadas por setor.

Tabela 1 - Quantidade de combinações de negócios realizadas por setor de 2010 a 2013

\begin{tabular}{l|c|c|c|c|c}
\hline Setores & $\mathbf{2 0 1 0}$ & $\mathbf{2 0 1 1}$ & $\mathbf{2 0 1 2}$ & $\mathbf{2 0 1 3}$ & $\begin{array}{c}\text { Quantidade de Combinações de } \\
\text { Negócios por Setor }\end{array}$ \\
\hline Consumo Não Cíclico & 25 & 15 & 12 & 6 & 58 \\
\hline Consumo Cíclico & 7 & 23 & 16 & 8 & 54 \\
\hline Construção e transporte & 9 & 13 & 10 & 4 & 36 \\
\hline Financeiro e outros & 2 & 8 & 6 & 2 & 18 \\
\hline Bens industriais & 3 & 2 & 5 & 0 & 10 \\
\hline Utilidade Pública & 1 & 3 & 5 & 0 & 9 \\
\hline Materiais Básicos & 6 & 0 & 0 & 1 & 7 \\
\hline Tecnologia da Informação & 0 & 0 & 0 & 6 & 6 \\
\hline Telecomunicações & 0 & 2 & 1 & 0 & 3 \\
\hline Petróleo, Gás e Biocombustíveis & 1 & 0 & 0 & 0 & 1 \\
\hline \multicolumn{1}{c}{ Total } & $\mathbf{5 4}$ & $\mathbf{6 6}$ & $\mathbf{5 5}$ & $\mathbf{2 7}$ & $\mathbf{2 0 2}$ \\
\hline
\end{tabular}

Fonte: os autores. 
Com base na Tabela 1, percebe-se que os setores de consumo cíclico e não cíclico foram os que mais realizaram combinações de negócios no período de 2010 a 2013. No que se refere ao ano em que ocorreu a combinação de negócios, destacam-se: 54 combinações ocorridas em 2010; 66, em 2011; 55, em 2012 e 27 combinações realizadas no ano 2013. Para controlar a variável Ano de realização da combinação de negócios, foram inseridas três variáveis dummies (D - 1).

Em relação à variável qualitativa de controle Setor de atuação, verifica-se que no período de 2010 a 2013 o setor Financeiro apresentou 18 combinações de negócios, e o setor de Utilidade Pública realizou o montante de nove combinações de negócios. Nesse último, elencam-se as seguintes empresas pertencentes ao segmento de energia elétrica: Equatorial (1), Companhia de Transmissão de Energia Elétrica Paulista (CTEEP) (1), Multiner (1) e CPFL Energia (6). Do total das 202 combinações de negócios, 27 são identificadas como do setor financeiro ou elétrico.

Na Tabela 2 demonstra-se à estatística descritiva das variáveis numéricas utilizadas nesta pesquisa.

Tabela 2 - Estatística descritiva das variáveis quantitativas

\begin{tabular}{l|c|c|c|c|c}
\hline Variáveis & Obs. & Média & Desvio Padrão & Mínimo & Máximo \\
\hline Disclosure & 202 & 0,29888 & 0,10438 & 0,07895 & 0,66667 \\
Price to Book & 197 & 3,18083 & 2,96682 & $-0,95$ & 15,96 \\
Tamanho & 199 & 14,89329 & 1,35209 & 12,21223 & 20,06928 \\
ROA & 199 & $-0,18822$ & 32,14202 & $-357,31$ & 23,1202 \\
Endividamento & 199 & 52,66519 & 17,59134 & 17,04 & 111,63 \\
Goodwill Relativo & 199 & 0,69219 & 1,28089 & 0 & 16,63633 \\
Porte Relativo & 196 & 0,05501 & 0,10221 & 0,00001 & 0,7779 \\
Número de Combinações & 202 & 3,27723 & 2,18597 & 1 & 8 \\
\hline
\end{tabular}

Fonte: os autores.

Nota: Disclosure = índice de evidenciação das combinações de negócios;

Price To Book = razão entre o valor da ação e o valor patrimonial da empresa por ação;

Tamanho = logaritmo natural do ativo total;

Rentabilidade do Ativo (ROA) = razão entre o resultado líquido do período e o ativo total;

Endividamento = razão entre o passivo total e o ativo total;

Goodwill Relativo = razão entre o goodwill e o valor da contraprestação da combinação de negócios;

Setor = variável dummy indicativa do setor financeiro ou de energia elétrica;

Porte Relativo = razão entre o valor da contraprestação da combinação de negócios e o ativo total;

Número de Combinações = quantidade de combinações de negócios realizadas no ano.

No que se refere ao disclosure das combinações de negócios, encontrou-se uma média de evidenciação de cerca de 30\% dos itens da métrica de análise do estudo. 
Além disso, em relação à quantidade de combinações realizadas no período de 2010 a 2013, identificou-se que as empresas analisadas realizaram entre 1 e 8 combinações de negócios por ano.

Para diagnóstico inicial de multicolinearidade do modelo de regressão, procedeu-se a análise da matriz de correlação das variáveis quantitativas, de acordo com a Tabela 3.

Tabela 3 - Matriz de correlação das variáveis quantitativas

\begin{tabular}{|c|c|c|c|c|c|c|c|c|}
\hline & $\begin{array}{l}0 \\
\stackrel{\overline{3}}{0} \\
\stackrel{0}{0} \\
.0 \\
\stackrel{0}{0}\end{array}$ & $\begin{array}{l}y \\
0 \\
0 \\
0 \\
0 \\
0 \\
0 \\
0 \\
0\end{array}$ & $\begin{array}{c}\stackrel{0}{\Xi} \\
\stackrel{\Xi}{\Xi} \\
\stackrel{\Xi}{\Xi} \\
\stackrel{\Xi}{\Xi}\end{array}$ & $\begin{array}{l}\overleftrightarrow{\vdots} \\
\approx\end{array}$ & 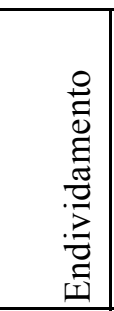 & 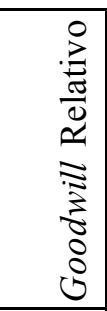 & 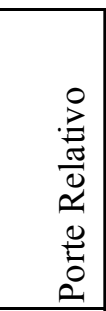 & 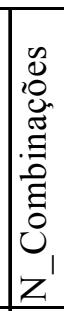 \\
\hline Disclosure & 1 & & & & & & & \\
\hline Price to Book & $-0,012$ & 1 & & & & & & \\
\hline Tamanho & $-0,006$ & $-0,366$ & 1 & & & & & \\
\hline ROA & $-0,141$ & 0,0673 & 0,0219 & 1 & & & & \\
\hline Endividamento & $-0,006$ & 0,0878 & 0,3344 & $-0,055$ & 1 & & & \\
\hline Goodwill Relativo & $-0,122$ & $-0,045$ & $-0,082$ & 0,0186 & 0,0032 & 1 & & \\
\hline Porte Relativo & 0,2133 & 0,0778 & $-0,141$ & $-0,014$ & $-0,024$ & $-0,052$ & 1 & \\
\hline N_Combinações & $-0,185$ & 0,2782 & $-0,235$ & 0,1316 & $-0,198$ & $-0,019$ & $-0,219$ & 1 \\
\hline
\end{tabular}

Fonte: os autores.

Nota-se uma correlação negativa entre a proporção do goodwill em relação à contraprestação e o nível de disclosure das combinações de negócios e uma correlação positiva entre a proporção da contraprestação em relação ao total de seus ativos e o nível de disclosure das combinações de negócios. Ambas as correlações estão de acordo com as hipóteses de pesquisa formuladas.

Por meio da matriz de correlação apresentada na Tabela 3, constata-se que a maior correlação verificada entre as variáveis explicativas é de -0,3660 entre tamanho e price to book. Desse modo, conclui-se que as correlações encontradas são baixas, o que é um indicativo de que o modelo analisado nesta pesquisa não apresenta problemas de multicolinearidade.

Também se procedeu a análise da estatística Variance Inflation Factor (VIF). Conforme Fávero et al. (2009, p. 259), “[...] a estatística VIF é uma medida de quanto 
a variância de cada coeficiente de regressão estimado aumenta devido à multicolinearidade.” Os resultados da estatística VIF são demonstrados na Tabela 4.

\begin{tabular}{l|c|c}
\multicolumn{3}{l}{ Tabela 4 - Estatística VIF das variáveis explicativas e de controle } \\
\hline Variáve is & VIF & $\mathbf{1 / V I F}$ \\
\hline Price to Book & 1,43 & 0,698127 \\
\hline Tamanho & 1,5 & 0,66878 \\
\hline ROA & 1,1 & 0,912841 \\
\hline Endividamento & 1,33 & 0,754552 \\
\hline Goodwill Relativo & 1,04 & 0,957793 \\
\hline Porte Relativo & 1,17 & 0,853932 \\
\hline Número de Combinações & 1,39 & 0,717907 \\
\hline Setor & 1,14 & 0,881025 \\
\hline Ano2011 & 1,81 & 0,552047 \\
\hline Ano2012 & 1,79 & 0,558267 \\
\hline Ano2013 & 1,41 & 0,708675 \\
\hline Média VIF & $\mathbf{1 , 3 7}$ & \\
\hline
\end{tabular}

Fonte: os autores.

Observa-se, conforme a Tabela 4, que a estatística VIF apresenta valores menores do que 2, indicando a inexistência de problemas de multicolinearidade.

A Tabela 5 mostra os resultados encontrados a partir da análise de regressão.

Tabela 5 - Resultados da análise de regressão - variável dependente: Disclosure

\begin{tabular}{|c|c|c|c|c|}
\hline Disclos ure & Coeficiente & Std. Err. & $\mathbf{t}$ & $\mathbf{P}>\mathbf{t}$ \\
\hline Price to Book & 0,00333 & 0,00274 & 1,22 & 0,225 \\
\hline Tamanho & 0,00104 & 0,00666 & 0,16 & 0,876 \\
\hline ROA & $-0,00031$ & 0,00018 & $-1,71$ & 0,088 \\
\hline Endividamento & 0,00022 & 0,00056 & 0,39 & 0,693 \\
\hline Goodwill Relativo & $-0,0116$ & 0,0033 & $-3,51$ & 0,001 \\
\hline Porte Relativo & 0,2158 & 0,06587 & 3,28 & 0,001 \\
\hline Número de Combinações & $-0,00638$ & 0,00416 & $-1,53$ & 0,127 \\
\hline Setor & $-0,02998$ & 0,01748 & $-1,72$ & 0,088 \\
\hline Ano2011 & 0,08433 & 0,02131 & 3,96 & 0 \\
\hline Ano 2012 & 0,07459 & 0,02126 & 3,51 & 0,001 \\
\hline Ano 2013 & 0,04946 & 0,02289 & 2,16 & 0,032 \\
\hline cons & 0,22733 & 0,09419 & 2,41 & 0,017 \\
\hline Número de Obs. & 195 & \multicolumn{2}{|c|}{$\mathrm{F}(11,183)$} & 5,27 \\
\hline R-Quadrado Ajustado & 0,1883 & \multicolumn{2}{|c|}{ Prob $>$ F } & 0 \\
\hline
\end{tabular}

Fonte: os autores. 
O modelo de regressão mostra-se significativo como um todo, uma vez que a probabilidade da Estatística $\mathrm{F}$ foi menor que 0,05, o que indica que a hipótese de que os parâmetros estimados são conjuntamente iguais a zero foi refutada.

Ressalta-se que o modelo de regressão foi calculado com estimadores robustos. Apesar de os testes para heterocedasticidade de Breusch-Pagan e Cook-Weisberg não rejeitarem a hipótese nula de variância constante para os resíduos, o nível de significância obtido foi de 10,88\% (Prob. > chi2 = 0,1088).

Os coeficientes das variáveis explicativas estatisticamente significantes do modelo foram: goodwill relativo e porte relativo, significantes ao nível de 1\%, e ROA, ao nível de 10\%. Esses resultados corroboram o estudo de Shalev (2009) no qual o autor observou uma correlação negativa entre o goodwill relativo (razão entre o goodwill e o valor da contraprestação da combinação de negócios) e o nível de disclosure das combinações de negócios.

Conforme Nakayama e Salotti (2014), isso indica que entidades adquirentes com menor ativo total tendem ao reconhecimento de maiores valores de goodwill na transação. O coeficiente do porte relativo mostrou-se positivo e significativo, conforme também verificado pelos autores. Isso mostra que entidades adquirentes divulgam maiores informações sobre combinações de negócios quanto maior for a representatividade do valor da contraprestação da combinação de negócios em relação ao seu ativo total.

Quanto às variáveis de controle utilizadas (Setor e Ano), estas apresentaram coeficientes significativos. Além disso, o poder explicativo do modelo foi 18,83\%, ou seja, o modelo explica 18,83\% dos fatores que motivam o disclosure de combinações de negócios realizadas por empresas brasileiras.

\section{CONCLUSÃO}

O estudo demonstrou que as empresas brasileiras que realizaram combinações de negócios nos anos 2010 e 2013 apresentaram, em média, um baixo nível de evidenciação, confirmando os resultados demonstrados por Nakayma e Salotti (2014), que verificaram a evidenciação na adoção inicial da norma CPC-15 no ano 2010. Pode-se inferir que o nível de evidenciação realizado pelas empresas brasileiras ainda apresenta deficiências.

A variável Goodwill relativo se mostrou negativamente relacionada ao nível de disclosure, ao nível de 1\%, o que sugere que quanto maior a parcela da contraprestação alocada ao goodwill, menor o nível de evidenciação da combinação de negócios nas empresas brasileiras. Shalev (2009) também encontrou resultados semelhantes 
analisando empresas nos Estados Unidos. Já no estudo de Nakayama e Salotti (2014) essa variável não se mostrou significativa, possivelmente pela análise ter se restringido ao ano de adoção inicial da norma.

A variável Porte relativo se apresentou positivamente relacionada ao nível de disclosure, corroborando os resultados de Nakayama e Salotti (2014). Essa relação positiva sugere que, em média, as empresas adquirentes tendem a divulgar um maior nível de informações sobre as combinações de negócios quando o valor da contraprestação em relação aos seus próprios ativos é significativo.

A variável Rentabilidade se mostrou significativa ao nível de $10 \%$, com coeficiente negativo, o que indica que as adquirentes com menor índice de rentabilidade tenderam, em média, a realizar um maior nível de divulgação relativo à combinação de negócios.

No que se refere à Transparência, notou-se que as empresas brasileiras ainda precisam evoluir na maneira como evidenciam suas combinações de negócios, visto que a média de evidenciação foi inferior a 50\%.

Ressalta-se que os resultados desta pesquisa se limitam à amostra e período pesquisados. Dessa maneira, os resultados não podem ser extrapolados para outras empresas e períodos posteriores.

Como sugestão para trabalhos futuros seria possível uma análise mais abrangente incluindo variáveis adicionais de análise, como, por exemplo: existência de Comitê de Auditoria, quantidade de membros externos no Comitê de Auditoria e no Conselho de Administração e outras variáveis envolvendo a boa governança corporativa das companhias brasileiras.

\section{REFERÊNCIAS}

AZEVEDO, C. E. F. et al. A estratégia de triangulação: objetivos, possibilidades, limitações e proximidades com o pragmatismo. In: ENCONTRO DE ENSINO E PESQUISA EM ADMINISTRAÇÃO E CONTABILIDADE - ENEPQ, 4., 2013, Brasília, DF. Anais... Brasília, DF: EnEPQ, 2013.

BABOUKARDOS, D.; RIMMEL, G. Goodwill under IFRS: relevance and disclosures in anunfavorable environment. Accounting Forum, v. 38, p. 1-17, 2014.

BARDIN, L. Análise de conteúdo. 3. ed. Lisboa: Edições 70, 2004.

BEHNAME, M.; PAJOOHI, M. R.; GHAHRAMANIZADY, M. The relationship between intangible assets and the market value; metals industry of Tehran stock exchange case study. Australian Journal of Basic and Applied Sciences, v. 6, i. 12, p. 115-122, 2012. 
BUSHMAN, R. et al. The sensitivity of corporate governance systems to the timeliness of accounting earnings. SSRN, 2000. Disponível em: <http://ssrn.com/abstract=241939>. Acesso em: 28 jun. 2016.

BUSHMAN, R. M.; SMITH, A. J. Transparency, financial accounting information, and corporate governance. FRBNY Economic Policy Review, 2003.

\section{COMITÊ DE PRONUNCIAMENTOS CONTÁBEIS. Pronunciamento Técnico}

CPC 15 R1. Combinação de negócios. 2011. Disponível em: <http://www.cpc.org. br/CPC>. Acesso em: 31 maio 2014.

COOPER, R.; KAPLAN, R. S. Measure costs right: make the right decisians. Harvard Business Review, p. 96-103, 1988.

CUNHA, J. V. A. da; COELHO, A. C. Regressão linear múltipla. In: CORRAR, L. J.; PAULO, E.; DIAS FILHO, J. M. (Org.). Análise multivariada: para os cursos de administração, ciências contábeis e economia. São Paulo: Atlas, 2009.

DORATA, N. T.; ZALDIVAR, I. P. Fair value and business combinations. Review of Business, v. 30, i. 2, 2010.

FÁVERO, L. P. et al. Análise de dados: modelagem multivariada para tomada de decisões. Rio de Janeiro: Campus Elsevier, 2009.

FIELDS, T. D.; LYS, T. Z.; VINCENT L. Empirical research on accounting choice. Journal of Accounting and Economics, v. 31, p. 255-307, 2001.

FOGG, D. C. New business planning: the acquisition process. Industrial marketing management, v. 5, p. 95-113, 1976.

GODOY, C. R. de; SANTOS, A. Contabilidade para fusões e aquisições de empresas: soluções históricas para problemas contemporâneos. Revista de Administração da USP, São Paulo, v. 41, n. 1, p. 29-42, 2006.

HASSAN, O. A. G. et al. The value relevance of disclosure: evidence from the emerging capital market of Egypt. The International Journal of Accounting, v. 44, p. 79-102, 2009.

HEALY, P. M.; PALEPU, K. G.; RUBACK, R. S. Does corporate performance improve after mergers? Performance improve. Journal of Financial Economics, v. 31, p. 135-175, 1992. 
HEALY, P. M.; WAHLEN, J. M. A review of the earnings management literature and its implications for standards setting. Accounting Horizons, v. 13, i. 4, p. 365-383, 1999.

HOLTHAUSEN, R. W.; LEFTWICH, R. W. The economic consequences of accounting choice. Journal of Accounting and Economics, v. 5, p. 77-117, 1983.

JENSEN, M. C.; MECKLING, W. H. Theory of the firm: managerial behavior, agency costs and ownership structure. Journal of Financial Economics, v. 3, i. 4, 1976.

KLANN, R. C.; BEUREN, I. M.; HEIN, N. Canonical relationship between performance indicators based on Brazil, US and IFRS accounting standards of Brazilian and United Kingdom companies. Journal of Accounting and Taxation, v. 7, p. 1-12, Jan. 2015.

LA PORTA, R. et al. Investor protection and corporate governance. Journal of Financial Economics, v. 58, p. 3-27, 2000.

MARIO, C. et al. The impact of IFRS on reporting for business combinations: an in-depth analysis using the telecommunications industry. Annals of Faculty of Economics, v. 1, i. 1, p. 557-593, 2011.

MARTINEZ, A. L. Gerenciamento dos resultados contábeis: um estudo empírico das companhias abertas brasileiras. 2001. 167 p. Tese (Doutorado em Contabilidade e Controladoria)-Universidade de São Paulo, São Paulo, 2001.

MORTENSEN, Roger. Accounting for business combinations in the global economy: purcharge, pooling, or? Journal of Accounting Education, v. 12, i. 1, p. 81-87, 1994.

NAKAYAMA, W. K. Divulgação de informações sobre operações de combinação de negócios na vigência do pronunciamento técnico CPC 15. 2012. 153 p. Dissertação (Mestrado em Ciências Contábeis)-Universidade de São Paulo, São Paulo, 2012.

NAKAYAMA, W. K.; SALOTTI, B. M. Fatores determinantes do nível de divulgação de informações sobre combinações de negócios com a entrada em vigor do pronunciamento técnico CPC 15. Revista de Contabilidade \& Finanças, v. 25, n. 66, p. 267-280, 2014. 
PAE, J.; THORNTON, D. B.; WELKER, M. The link between earnings conservatism and the price to book ratio. Contemporary Accounting Research, v. 22, i. 3, 2005. Disponível em: <http://ssrn.com/abstract=722545>. Acesso em: 03 maio 2015.

PALMER, P. D. Disclosure of the impacts of adopting Australian equivalents of International Financial Reporting Standards. Accounting and Finance, v. 48, p. 847-870, 2008.

PATEL, S. A.; BALIC, A.; BWAKIRA, L. Measuring transparency and disclosure at firm level in emerging markets. Emerging Markets Review, v. 3, p. 325-337, 2002.

SCHIPPER, K. Required disclosures in financial reports. The Accounting Review, v. 82, i. 2, p. 301-326, 2007.

SHALEV, R. The information content of business combination disclosure level. The Accounting Review, v. 84, p. 239-270, 2009.

SILVEIRA, A. D. M. da et al. Efeito dos acionistas controladores no valor das companhias abertas brasileiras. R. Adm., v. 39, n. 4, p. 362-372, 2004.

SILVEIRA, A. D. M. da. Governança corporativa e estrutura de propriedade: determinantes e relação com o desempenho das empresas no Brasil. 2004. 250 p. Tese (Doutorado em Contabilidade e Controladoria)-Universidade de São Paulo, São Paulo, 2004.

SHLEIFER, A.; VISHNY, R. W. A survey of corporate governance. The Journal of Finance, v. 52, i. 2, p. 737-783, June 1997.

SOUZA, M. M. de. Value relevance do nível de disclosure das combinações de negócios e do goodwill reconhecido nas empresas brasileiras. 2015. 183 p. Tese (Doutorado em Administração)-Universidade Federal de Santa Catarina, Florianópolis, 2015.

WATTS, R. Accounting choice theory and market-based research in accounting. British Accounting Review, v. 24, p. 235-267, 1992. 
Como citar este artigo:

\section{ABNT}

SOUZA, Maíra Melo; ROVER, Sualiani; BORBA, José Alonso. Determinantes do nível de disclosure das combinações de negócios realizadas pelas empresas de capital aberto brasileiras. RACE, Revista de Administração, Contabilidade e Economia, Joaçaba: Ed. Unoesc, v. 15, n. 3, p. 945-968, set./dez. 2016. Disponível em: $<$ http://editora.unoesc.edu.br/index.php/race>. Acesso em: dia/mês/ano.

\section{APA}

Souza, M. M., Rover, S., \& Borba, J. A. Determinantes do nível de disclosure das combinações de negócios realizadas pelas empresas de capital aberto brasileiras. RACE, Revista de Administração, Contabilidade e Economia, 15(3), 945-968. Recuperado em dia/mês/ano, de http://editora.unoesc.edu.br/index.php/race 